\title{
An Effective Tool for Column Evaluation in the Analysis of Basic Compounds
}

\author{
Cinzia Stella ${ }^{a \star}$, Patrick Seuret ${ }^{a}$, Serge Rudaz $^{a}$, Pierre-Alain Carrupt ${ }^{b}$, Jean-Yves Gauvrit ${ }^{c}$, \\ Pierre Lanteric ${ }^{c}$ and Jean-Luc Veutheya
}

\begin{abstract}
A chromatographic test is described for the evaluation of base-deactivated stationary phases. Seven test basic compounds, selected on their physico-chemical properties, were injected with two differ-

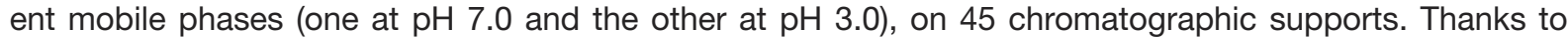
the measured chromatographic parameters ( $k$ and As), it was possible to evaluate both silanol activity and hydrophobic character of the base-deactivated columns. In addition, the validity of this chromatographic test was assessed by measuring the fundamental properties of the same supports with a general test protocol, issued from the literature.
\end{abstract}

Keywords: Basic compounds · Chromatographic test · High-performance liquid chromatography · Principal component analysis

${ }^{\star}$ Correspondence: Dr. C. Stella ${ }^{a}$

$\mathrm{CH}-1211$ Geneva 4

Tel.: +41227026102

Fax: +41227815193

E-Mail: cinzia.stella@pharm.unige.ch

aLaboratory of Pharmaceutical Analytical Chemistry

20, bd. d'Yvoy

University of Geneva

bInstitute of Medicinal Chemistry

BEP - Dorigny

$\mathrm{CH}-1015$ Lausanne

cLaboratory of Chemometrics

University of Lyon

ESPCE-69622 Villeurbanne, France

\section{Introduction}

Basic compounds appear in widely differing areas, such as the environmental, chemical, food, and pharmaceutical industries. In the latter in particular, over $80 \%$ of commercialized drugs are estimated to possess a basic function. Therefore, it is of crucial importance to develop efficient methods for the analysis of these compounds in several domains such as quality control, forensic and clinical analysis, therapeutic monitoring, metabolism studies, etc.

Reversed phase liquid chromatography (RPLC) is currently the method of choice for the analysis of these compounds. However, with traditional silica packings, secondary interactions between analyte and residual silanols induce peak tailing which affects resolution, sensitivity and reproducibility. In order to overcome this, several stationary phases have been developed with specially designed groups which reduce accessibility to free silanols [1][2].

Today, more than 300 'base-deactivated' or 'special base' stationary phases are commercialized. Unfortunately, there is still no universally accepted chromatographic test to select an appropriate column for a particular separation [3]. The great number of tests present in the literature can be classified into two groups: 1) general tests and 2) particular tests. The aim of general tests is to afford knowledge of the dif- ferent interactions between the analytes and the stationary phases. For example, some parameters such as ion exchange capacity, silanol retention capacity, hydrophobic retention as well as bonding density and alkyl chains length can be determined. These general tests are known as the Engelhardt, Tanaka, Sander and Wise tests [4][5].

In the case of basic compounds the situation is more complex. The chromatographic behavior of a given column can be strongly influenced by the physico-chemical properties of the test solute and easily influenced by many factors such as the $\mathrm{pH}$ and composition of the mobile phase. For this reason, it is recommended to perform column evaluation with a set of test compounds covering a wide range of $\mathrm{p} K_{a}$ values and chemical structures [6]. In addition, column testing in unbuffered mobile phases is inadequate to evaluate stationary phases with ionizable and strongly basic compounds [7].

In this work, different base-deactivated supports were evaluated with a particular chromatographic test previously developed [8][9]. The reversed-phase columns were tested with two different mobile phases (one at $\mathrm{pH} 7.0$ and another at $\mathrm{pH}$ 3.0) and seven basic test compounds, selected partly on the basis of McCalley studies [10][11], and partly on studies performed in our laboratory. In addition, batch and column variability were evaluated by testing three 
columns of different batches for each support. For a simplified graphical representation of this complex data system, principal component analysis (PCA) was chosen.

In addition, the column evaluation obtained was compared with the one obtained with general tests on the same supports. The aim of this comparison was to confirm the results obtained with our chromatographic test.

\section{Experimental}

The test solutes used for the characterization of the chromatographic supports were of analytical reagent grade and were obtained from different sources: quinine and methadone from Hänseler (Herisau, Switzerland); procaïnamide, pyridine and nicotine from Fluka (Buchs, Switzerland); fentanyl form Macfarlan (Edinburgh, Scotland) and chloroprocaïne from Orgamol (Evionnaz, Switzerland).

Acetonitrile and methanol were of HPLC gradient grade from SDS (Peypin, France).

Water was obtained with the Milli-Q Water Purification System from Millipore (Milford, MA, USA). Aqueous buffers were prepared with di-potassium hydrogen phosphate anhydrous (Fluka-Buchs, Switzerland) and potassium dihydrogen phosphate (Fluka-Buchs, Switzerland) by measuring the $\mathrm{pH}$ with a Metrohm $\mathrm{pH}$ meter (Herisau, Switzerland). The $\mathrm{pH}$ measured corresponded to the $\mathrm{pH}$ in the buffer (without methanol or acetonitrile). The tested columns and their characteristics are listed in the Table.

Column testing was performed with a Merck-Hitachi LiChrograph constituted of a L-6200 programmable pump, an AS-2000 automatic injector with $100 \mu \mathrm{l}$ loop and a L-4250 UV-VIS programmable detector operating at $215 \mathrm{~nm}$. Data acquisition and evaluation were performed by the D-7000 HPLC System Manager Software. Connections were made with minimum lengths of $0.25 \mathrm{~mm}$ I.D. tubing.

\section{Results and Discussion}

The selected chromatographic supports (three column of different batches/ support) were tested with the following mobile phases:

- Mobile phase 1: acetonitrile - $\mathrm{pH} 7.0$,

$0.0375 \mathrm{M}$ phosphate buffer (40:60, v/v)

- Mobile phase 2: acetonitrile - $\mathrm{pH} 3.0$,

$0.0265 \mathrm{M}$ phosphate buffer $(15: 85, \mathrm{v} / \mathrm{v})$ and for each injected basic test compound the following chromatographic parameters were measured: the retention $(k)$ and the asymmetry factor (As). That means a total of 252 chromatographic parameters to be treated with PCA for the evaluation of each selected support (Fig. 1).

In mobile phase 1 ( $\mathrm{pH} 7.0)$ both free silanols and basic compounds are ionized and thus strong ion exchange interactions can occur, leading to unfavorable peak tailing. Therefore, chromatographic columns will here be differentiated with respect to their capacity to mask silanol groups (Fig. 2).

Embedded polar group (Stability BS $\mathrm{C}_{23}$, Discovery RP Amide $\mathrm{C}_{16}$, Supelcosil ABZ Plus, Nucleosil $C_{18}$ Nautilus), as well as monolith (Performance) and hybrid supports (Xterra RP 18), showed a good batchto-batch reproducibility in comparison to bidentate (Zorbax Extend $\mathrm{C}_{18}$ ), high density (Zorbax Eclipse, Luna, Nucleosil HD), polymeric (Nucleosil $\mathrm{AB}$ ) and ultra pure silica (Nucleodur) supports in this particular mobile phase. The latter were also the supports showing the highest asymmetry factor in the analysis of basic compounds, being in the direction of the average asymmetry vector (Fig. 2). On the other hand, the supports possessing an embedded polar group in the bonded chain showed the best performances in terms of asymmetry. On the basis of the above column evaluation (Fig. 2), we decided to investigate whether the less adapted supports, for the analysis of basic compounds, effectively possess a

\begin{tabular}{|c|c|c|c|c|c|}
\hline & $\begin{array}{l}\text { Alkyl } \\
\text { chain }\end{array}$ & $\begin{array}{l}\text { Bonding } \\
\text { type }\end{array}$ & $\begin{array}{l}\text { Particle } \\
\text { size / } \\
\text { pores }\end{array}$ & $\begin{array}{l}\text { Column } \\
\text { dimensions } \\
\text { [mm] }\end{array}$ & Manufacturer \\
\hline Acclaim & $\mathrm{C}_{18}$ & - & $5 \mu \mathrm{m} / 120 \AA$ & $4.6 \times 150$ & Dionex ${ }^{\circledR}$ \\
\hline $\begin{array}{l}\text { Chromolith } \\
\text { Performance }\end{array}$ & $\mathrm{C}_{18}$ & Monolith & - & $4.6 \times 100$ & Merck $^{\circledR}$ \\
\hline $\begin{array}{l}\text { DiscoveryRP } \\
{\text { Amide } C_{16}}\end{array}$ & $\mathrm{C}_{16}$ & Polar group & $5 \mu \mathrm{m} / 100 \AA$ & $4.6 \times 150$ & Supelco ${ }^{\circledR}$ \\
\hline $\begin{array}{l}\text { Zorbax Eclipse } \\
\text { XDB }\end{array}$ & $\mathrm{C}_{18}$ & High density & $5 \mu \mathrm{m} / 100 \AA$ & $4.6 \times 150$ & Agilent ${ }^{\circledR}$ \\
\hline Luna & $\mathrm{C}_{18}$ & High density & $5 \mu \mathrm{m} / 100 \AA$ & $4.6 \times 150$ & Phenomenex ${ }^{\circledR}$ \\
\hline Nucleodur & $\mathrm{C}_{18}$ & - & $5 \mu \mathrm{m} / 100 \AA$ & $4.0 \times 125$ & Macherey-Nagel ${ }^{\circledR}$ \\
\hline $\begin{array}{l}\text { Nucleosil } \\
C_{18} A B\end{array}$ & $\mathrm{C}_{18}$ & $\begin{array}{l}\text { Polymeric } \\
\text { bonding }\end{array}$ & $5 \mu \mathrm{m} / 100 \AA$ & $4.0 \times 125$ & Macherey-Nagel ${ }^{\circledR}$ \\
\hline Nucleosil HD & $\mathrm{C}_{18}$ & High density & $5 \mu \mathrm{m} / 100 \AA$ & $4.0 \times 125$ & Macherey-Nagel ${ }^{\circledR}$ \\
\hline $\begin{array}{l}\text { Nucleosil } C_{18} \\
\text { Nautilus }\end{array}$ & $\mathrm{C}_{18}$ & Polar group & $5 \mu \mathrm{m} / 100 \AA$ & $4.0 \times 125$ & Macherey-Nagel ${ }^{\circledR}$ \\
\hline $\begin{array}{l}\text { Stability } \\
\text { BS C }_{23}\end{array}$ & $\mathrm{C}_{23}$ & $\begin{array}{l}\text { Charged } \\
\text { polar group }\end{array}$ & $5 \mu \mathrm{m} / 100 \AA$ & $4.6 \times 250$ & CIL-Cluzeau $^{\circledR}$ \\
\hline $\begin{array}{l}\text { Supelcosil } \\
\text { ABZ Plus }\end{array}$ & $\mathrm{C}_{16}$ & Polar group & $5 \mu \mathrm{m} / 100 \AA$ & $4.6 \times 150$ & Supelco ${ }^{\circledR}$ \\
\hline Xterra RP C 18 & $\mathrm{C}_{18}$ & Hybrid support & $5 \mu \mathrm{m} / 100 \AA$ & $4.6 \times 150$ & Waters $^{\circledR}$ \\
\hline $\begin{array}{l}\text { Zorbax } \\
\text { Extend } C_{18}\end{array}$ & $\mathrm{C}_{18}$ & $\begin{array}{l}\text { Bidentate } \\
\text { bonding }\end{array}$ & $5 \mu \mathrm{m} / 100 \AA$ & $4.6 \times 150$ & Agilent ${ }^{\circledR}$ \\
\hline
\end{tabular}



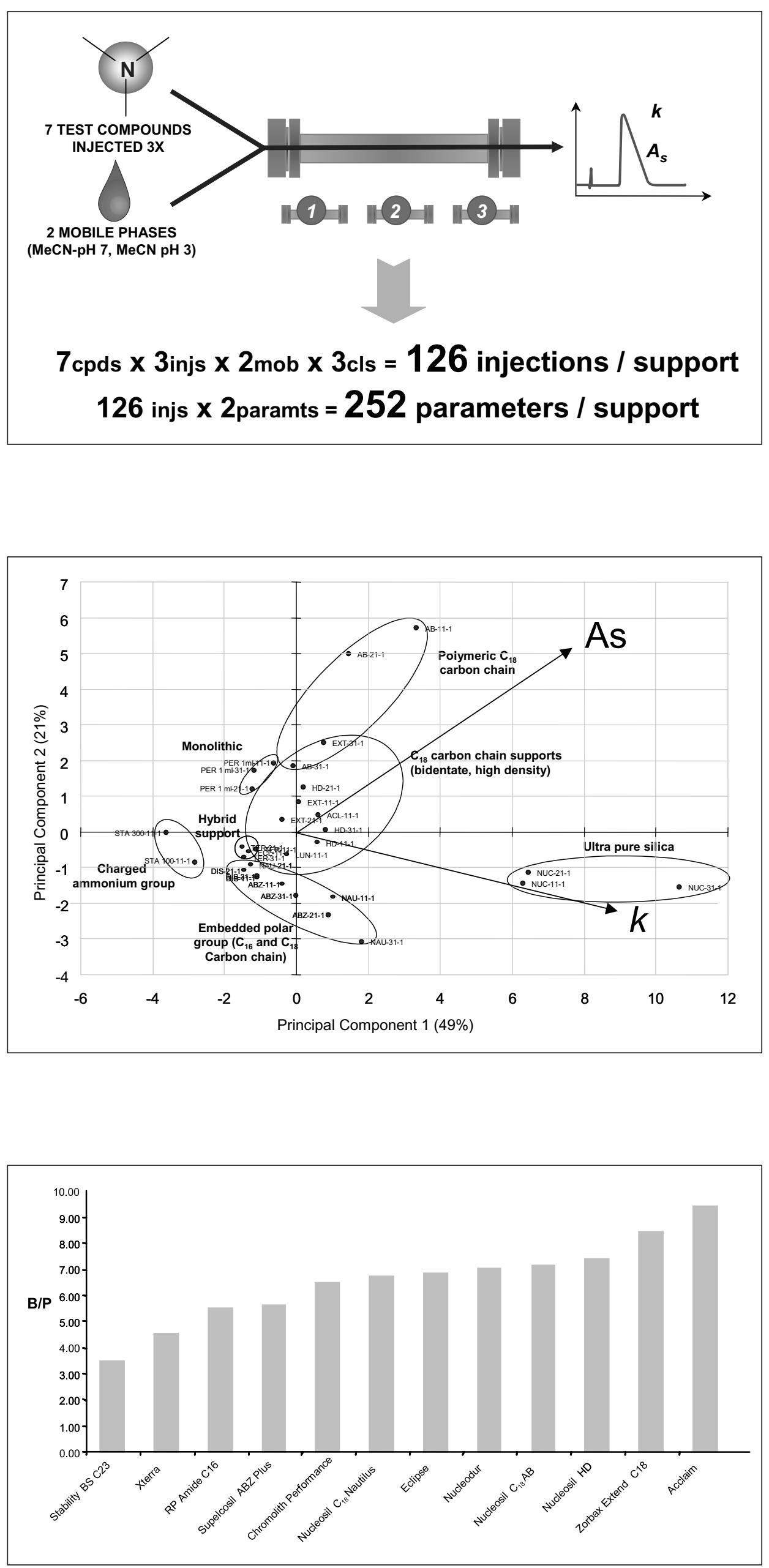

Fig. 1. Methodology

Fig. 2. Column evaluation in mobile phase 1 (pH 7.0)

Fig. 3. Silanol activity (general test) 
high silanol activity. With this aim, the same supports were evaluated with general tests. As expected, columns possessing the highest silanol activity (Fig. 3) were the ones placed in the direction of the average asymmetry vector in our column evaluation (Fig. 2).

Then chromatographic supports were tested with the mobile phase 2 ( $\mathrm{pH} 3.0)$. Given the great reduction of secondary interactions in this acidic $\mathrm{pH}$ mobile phase, chromatographic supports will here be classified especially in relation to their hydrophobic properties and thus bonding type. In fact, it was possible to clearly distinguish (Fig. 4): embedded polar group with $\mathrm{C}_{16}$ carbon chain, embedded polar group with $\mathrm{C}_{18}$ carbon chain, embedded ammonium polar group, monolith columns and $\mathrm{C}_{18}$ carbon chain. Among all tested supports, the ones possessing $\mathrm{C}_{18}$ carbon chains (polymeric, high density, bidentate, etc.) showed the highest hydrophobic character, being in the direction of the average retention vector. On the other hand, all embedded polar group supports (especially Stability $\mathrm{BS} \mathrm{C}_{23}$, possessing a charged polar group) showed a low hydrophobic character, due to their particular bonding.

In order to confirm these findings, the hydrophobic character of the same supports was also evaluated according to the general test protocol. As shown in Fig. 5, the supports (all $\mathrm{C}_{18}$ bonding types) possessing the highest retention values in our column evaluation, were also the ones possessing the highest hydrophobic character. The low hydrophobic character of embedded polar group supports (especially Stability $\mathrm{BS}_{23}$ ) was confirmed with the general test protocol.

\section{Conclusion}

The proposed test procedure is useful for characterizing base-deactivated columns. Thanks to this chromatographic test, the performances in the analysis of basic compounds (silanol activity) and the hydrophobic character of the supports could be revealed. In addition, by comparing this column evaluation with the results obtained according to general tests, the validity of our protocol was confirmed.

\section{Acknowledgements}

The authors would like to acknowledge Merck (Germany), Macherey Nagel (Germany) and Supelco (Switzerland) for kindly providing some of the tested supports. P. Wellhauser (Amtech-Chimie SA, Carrouge, Switzerland) is gratefully acknowledged for supporting this project.

Received: February 7, 2003

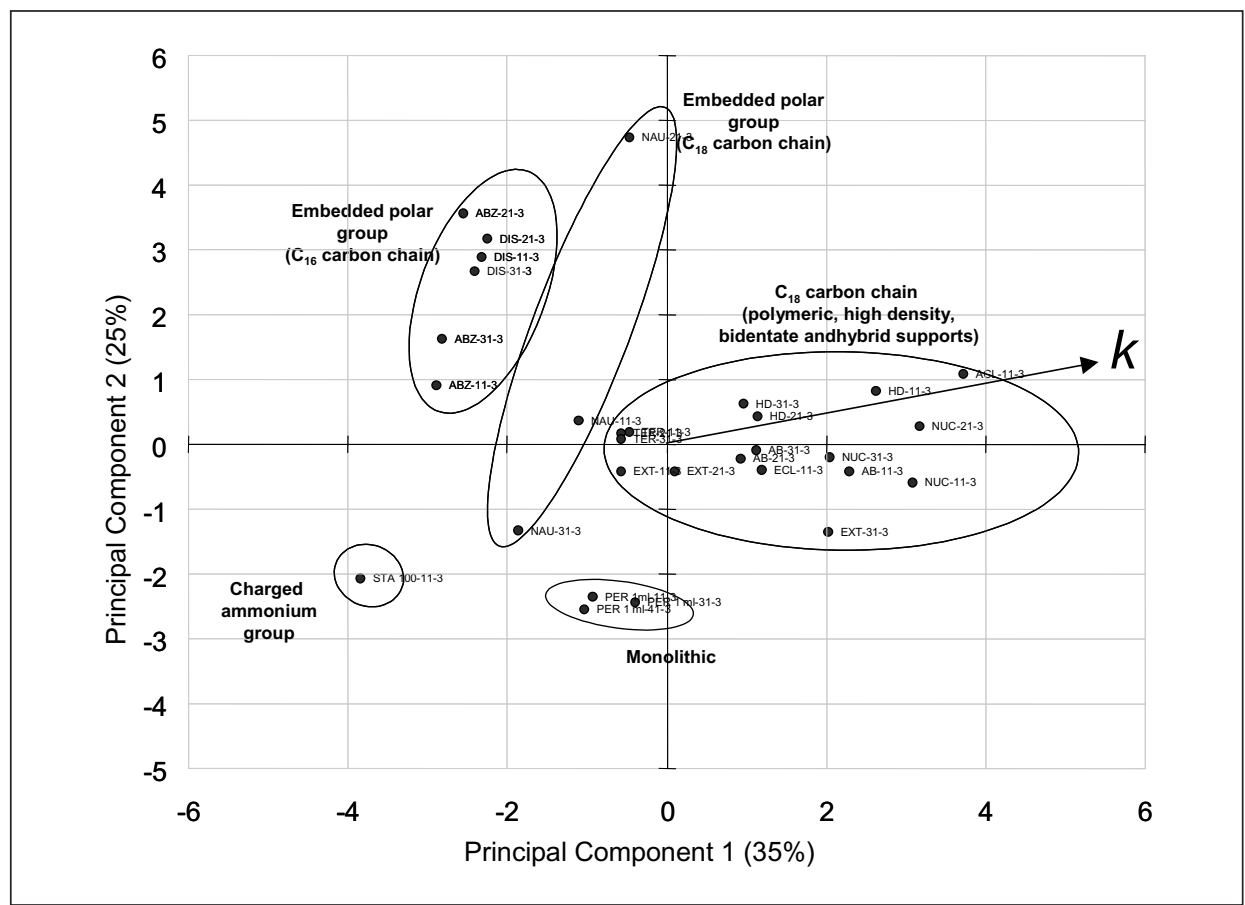

Fig. 4. Column evaluation in mobile phase $2(\mathrm{pH} 3.0)$

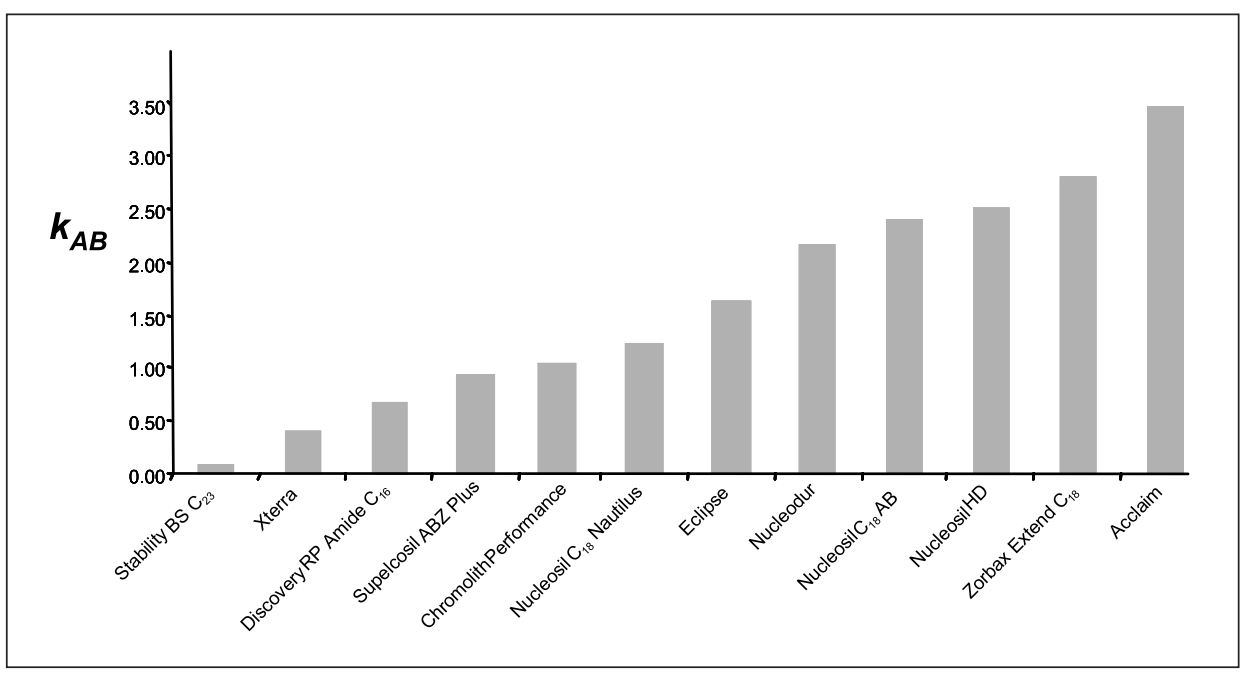

Fig. 5. Hydrophobic character (general test)

[1] S.D. Rogers, J.G. Dorsey, J. Chromatogr. A 2000, 892, 57.

[2] C. Stella, S. Rudaz, J.-L. Veuthey, A. Tchapla, Chromatographia 2001, 53, S-113.

[3] C. Stella, S. Rudaz, J.-L. Veuthey, A. Tchapla, Chromatographia 2001, 53, S-132.

[4] K. Kimata, K. Iwaguchi, S. Onishi, K. Jinno, R. Eksteen, K. Hosoya, M. Araki, N. Tanaka, J. Chromatogr. Sc. 1989, 27, 721.

[5] H. Engelhardt, M. Arangio, T. Lobert, $L C-G C$ 1997, 15, 856-865.

[6] J. Nawrocki, J. Chromatogr. A 1997, 779 29.

[7] D.V. McCalley, J. Chromatogr. A 1997, $769,169$.

[8] C. Stella, P. Seuret, S. Rudaz, P.-A. Carrupt, P.-A. Gauvrit, P. Lantéri, J.-L. Veuthey, J. Sep. Sc. 2002, 25, 1351.
[9] C. Stella, P. Seuret, S. Rudaz, A. Tchapla, P.-A. Gauvrit, P. Lantéri, J.-L. Veuthey, Chromatographia 2002, 56, 665.

[10] D.V. McCalley, J. Chromatogr. A 1996, $738,169$.

[11] D.V. McCalley, R.G. Brereton, J. Chromatogr. A 1998, 828, 407. 